\title{
FNAC of Lymph Node - A Valuable Clue to Diagnosis of Toxoplasma Lymphadenitis
}

\author{
Haque WS ${ }^{\mathrm{a}}$, Yasmin $\mathrm{S}^{\mathrm{b}}$, Islam SMJ' ${ }^{\mathrm{c}}$, Ahmed I ${ }^{\mathrm{d}}$, Hossain $\mathrm{S}^{\mathrm{e}}$, Saha $\mathrm{D}^{\mathrm{f}}$
}

\begin{abstract}
Background: Fine needle aspiration cytology (FNAC) is now a days the initial investigation in most cases of superficial lymphadenopathy. In clinical practice both clinicians and cytopathologists are not commonly suspecting of Toxoplasma lymphadenitis (TL), though it may constitute a significant proportion of unexplained lymphadenitis. Careful cognizance of cytological findings can give valuable clue to the diagnosis of toxoplasmosis which can be confirmed by serological evidence.

Methods: This cross-sectional study was conducted in Department of Histopathology of Armed Forces Institute of Pathology (AFIP), Bangladesh from 01 July 2017 to 31 March 2018. FNAC smears of the patients with lymphadenopathy who reported for FNAC were examined and suspicion of toxoplasmosis was made on coexistence of abundance of 'tingible body macrophages' (TBM) and follicular center cells (FCC), small collections of epithelioid histiocytes and absence of necrosis and/or more than occasional giant cells. Serum enzyme linked immunosorbent sorbent assay (ELISA) for Toxoplasma IgM and IgG antibody was then performed in all cases that deemed suspicious for toxoplasmosis for confirmation of the diagnosis.
\end{abstract}

Results: Total 925 patients were examined by FNAC of lymph node. Among them 574 were categorized as reactive hyperplasia $(R H)$. Thirty two patients (5.74\%) of RH were suspected as TL and included in the study. Serum ELISA confirmed toxoplasmosis in 22 (68.75\%, twelve male and ten female) of these 32 cases. One among the positive cases revealed bradyzoites of Toxoplasma in the smear. The age of the patients diagnosed finally as TL spanned between 5 to 47 years (mean 28.59 11.51 years) though most frequent age group was 26 Yr to $35 \mathrm{Yr}$ (7 cases- $31.8 \%$ ).

Conclusion: A high index of suspicion of TL can be made on careful study of smears of FNAC of enlarged lymph node, diagnosis of which can then be confirmed by ELISA.

Key words: Toxoplasma, lymphadenitis, bradyzoite, FNAC, ELISA

(BIRDEM Med J 2018; 8(2): 103-107)

Author Information

a. Wasim Selimul Haque MBBS, MCPS, DCP, FCPS (Histopatology). Classified Specialist in Pathology, AFIP

b. Shamoli Yasmin MBBS, MCPS, DCP, FCPS (Histopatology). Classified Specialist in Pathology, AFIP

c. SK Md Jaynul Islam MBBS, MCPS, DCP, FCPS (Histopatology). Classified specialist and HOD dept of histopathology, AFIP

d. Ishtyaq Ahmed MBBS, MCPS, DCP, FCPS (Histopatology). Asst Prof, pathology, Armed Forces Medical College

e. Sowkat Hossain MBBS, MCPS, DCP, FCPS (Histopatology). Classified Specialist in Pathology, AFIP

f. Debashish Saha MBBS, FCPS (Chem Path), MMEd. Commandant AFIP

Address of Correspondence: Dr. Wasim Selimul Haque MBBS, MCPS, DCP, FCPS (Histopatology). Classified Specialist in Pathology, AFIP. E-mail: audrirodelawasim@gmail.com

Received: April 14, 2018

Accepted: April 15, 2018

\section{Introduction}

Toxoplasma gondii is a ubiquitous coccidian protozoan. It infects many animal species including humans. ${ }^{1}$ The definitive hosts are felines like cat, while intermediate hosts are man and other mammals. ${ }^{2}$ The disease is transmitted to humans predominantly by ingestion of undercooked or raw meat containing viable tissue cysts, or by ingesting food or water contaminated with oocyst ${ }^{3}$ or inoculation through skin. ${ }^{4}$ About $40 \%$ of adult population of the world is infected with this protozoan with higher prevalence in warm and humid climate. ${ }^{3}$ Toxoplasma infection may be congenital or acquired. When acquired, toxoplasmosis rarely harms human host, and in vast majority, the infection remains occult throughout life, causing damage only when cellular 
immunity is impaired. ${ }^{4}$ In small percentage of acquired infections symptoms ranging from mild to severe disease may result. ${ }^{1}$ The commonest clinical manifestation of the acquired disease is flu like symptoms with lymphadenopathy- also known as Piringer-Kuchinka lymphadenitis. $^{2}$

Diagnosis of toxoplasma lymphadenitis (TL) is crucial as it can be treated by medical management. Serology is mainstay of diagnosis. ${ }^{5}$ Although the prevalence of the infection is quite high, most of the acquired toxoplasmosis patients who present with lymphadenopathy are usually not suspected. They are advised for fine needle aspiration cytology (FNAC) as their first line investigation without the investigation of serology. Definite diagnosis of TL can be done if tissue cyst or bradyzoites are seen in the FNAC smears; a very rare finding in clinical practice. Rarely has the demonstration/identification of the morphologic stages of the parasite been reported. ${ }^{6,7}$ However, FNAC smears from lymph nodes affected by toxoplasmosis show some characteristic features in addition to features which are present in reactive hyperplasia of lymph node. Careful cognizance of those findings can give the clue of the diagnosis which can be confirmed by serological evidence.

Our study was to focus on those criteria which can be helpful for diagnosis of TL in FNAC. The study intends to justify consideration of toxoplasmosis in the differential diagnosis of lymphadenopathy during evaluation of FNAC smear of lymph node.

\section{Methods}

This cross-sectional study was conducted in the Department of Histopathology of Armed Forces Institute of Pathology (AFIP), Bangladesh. AFIP receives patients from all military hospitals and also from civilian population of Bangladesh. Duration of the study was 9 months spanning from 01 July 2017 to 31 March 2018. All the patients with lymphadenopathy who reported for FNAC were aspirated using $5 \mathrm{cc}$ syringe with 23G needle. Smears were stained with haematoxylin \& eosin (H\&E) and Papanicolaou stain after fixation in $95 \%$ ethanol for 30 minutes. Then they were properly evaluated. All malignant lesions e.g. lymphoid neoplasms and metastatic neoplasms were excluded. Cases of tuberculosis and acute suppurative lymphadenitis were also excluded from the study.
Cytologic suspicion of toxoplasmosis was made among the cases that were categorized as RH and were included in the study. The basis of cytologic suspicion of TL were coexistence of-

1. Conspicuous abundance of 'tingible body macrophages' (TBM),

2. Presence of many transformed follicular center cells (FCC),

3. Tiny collections or scattered epithelioid histiocytes having abundant cytoplasm,

4. Absence of necrosis and/or more than occasional giant cells.

Patients who were suspected of TL underwent serological test for Toxoplasma IgM and IgG antibodies by ELISA method. The cut off points for positive results for IgM and $\operatorname{IgG}$ were $>300$ and $>10$ units $/ \mathrm{ml}$ respectively.

\section{Results}

Total number of patients for lymph node FNAC was 925. Among them 117 patients were diagnosed of having malignant diseases (Lymphoid neoplasms and metastatic diseases), 232 patients were diagnosed as tuberculosis and 2 patients as acute suppurative lymphadenitis. The rest 574 patients were categorized as reactive hyperplasia. Among them 32 patients were suspected as TL on the basis of set criteria (Fig $1 \& 2$ ) and were included in the study. One among these cases in addition to the expected cytologic features demonstrated a bradyzoite in the smear (Fig 3).

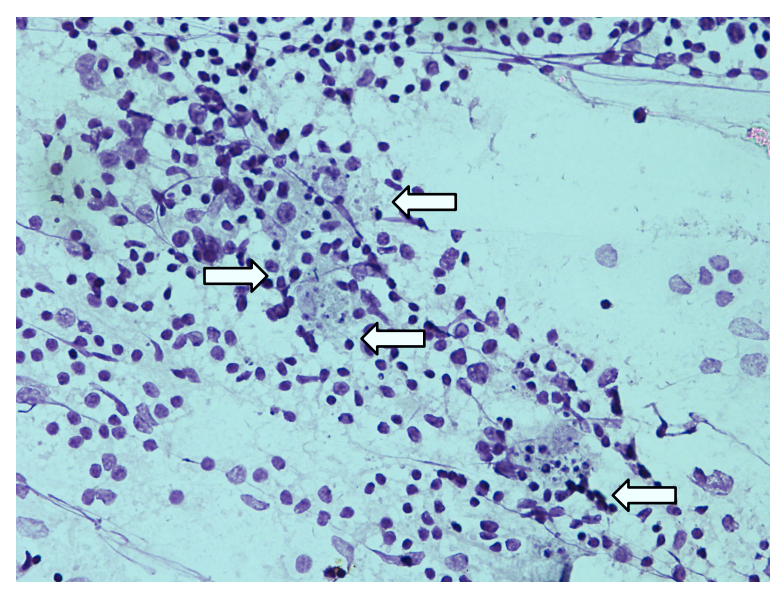

Figure 1. Many TBM (white arrow) among reactive lymphoid cells (Papanicolaou stain, X 400). 


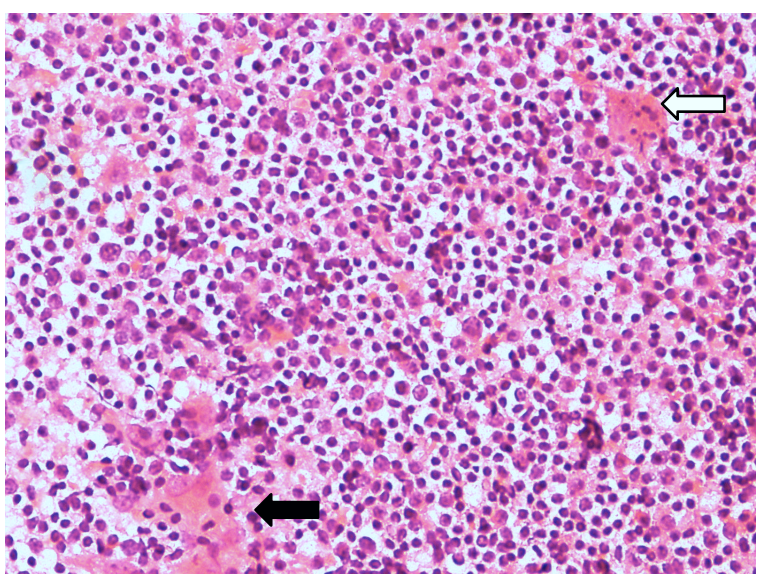

Figure 2. A TBM (white arrow) and a small collection epithelioid histiocytes (black arrow) among reactive lymphoid cells (H\&E stain, X 400).

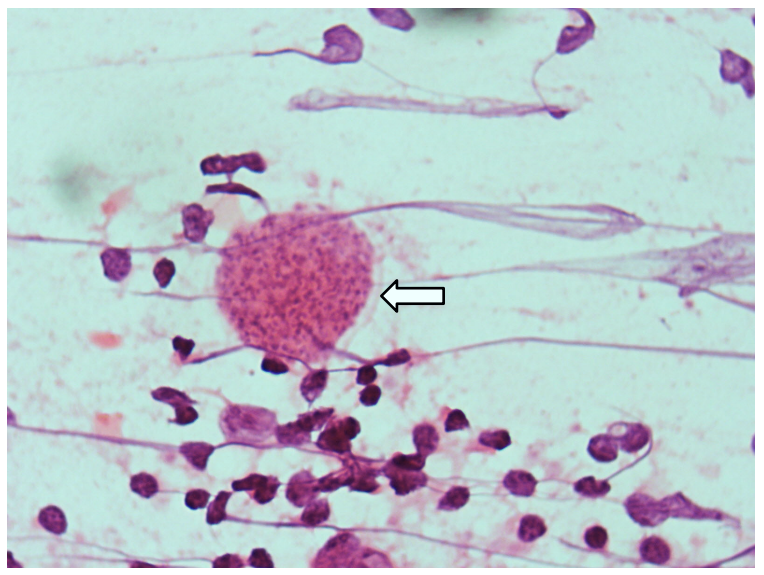

Figure 3. Tissue cyst (white arrow) containing numerous bradyzoites of $T$. gondii associated with a lymphoid cell population (H\&E stain, × 1,000).

All the 32 patients were investigated for serology of anti Toxoplasma antibody by ELISA. Serology confirmed toxoplasmosis in 22 patients. In all these 22 patients IgM were positive, mostly strongly (range 421-2493.6 ELISA unit/ml, average 1454.35 ELISA unit/ml). One but all of them were also positive for IgG (Table I). The rest 10 patients showed negative antibody titer.

Twenty two cases of TL constituted 2.38\% (22/925) of all lymph nodes aspirated for FNAC; on the other hand they represented $3.83 \%$ (22/574) of all RHs diagnosed during the period of study. However they encompassed $68.75 \%(22 / 32)$ of the suspected cases of TL.
Table I. Table showing ELISA for Toxoplasma antibody readings of positive cases $(\mathrm{N}-22)$

\begin{tabular}{|c|c|c|c|c|}
\hline SL & Age (Yr) & Sex & IgG(Unit/ml) & $\operatorname{IgM}($ Unit/ml) \\
\hline 1 & 42 & Female & 137.0 & 2351.5 \\
\hline 2 & 25 & Male & 174.5 & 2189.3 \\
\hline 3 & 42 & Male & 170.5 & 2345.5 \\
\hline 4 & 5 & Female & 25.5 & 1809.3 \\
\hline 5 & 47 & Male & 172.0 & 2094.2 \\
\hline 6 & 35 & Female & 165.9 & 895.5 \\
\hline 7 & 39 & Male & 122.6 & 2493.6 \\
\hline 8 & 19 & Female & 209.1 & 1469.1 \\
\hline 9 & 35 & Male & 10.0 & 421.0 \\
\hline 10 & 24 & Female & 108.3 & 808.9 \\
\hline 11 & 22 & Male & 147.0 & 1851.3 \\
\hline 12 & 45 & Female & 202.3 & 555.0 \\
\hline 13 & 28 & Male & 182.3 & 2418.4 \\
\hline 14 & 26 & Female & 118.5 & 1089.5 \\
\hline 15 & 22 & Female & 158.9 & 1142.6 \\
\hline 16 & 20 & Male & 174.7 & 1222.0 \\
\hline 17 & 33 & Male & 141.0 & 1240.3 \\
\hline 18 & 11 & Male & 191.4 & 1163.5 \\
\hline 19 & 40 & Female & 151.5 & 1414.5 \\
\hline 20 & 11 & Female & 192.0 & 1097.1 \\
\hline 21 & 27 & Male & 207.1 & 656.9 \\
\hline 22 & 31 & Male & 157.7 & 1266.9 \\
\hline
\end{tabular}

The age of the patients diagnosed finally as TL ranged between 5 to 47 years (mean 28.59 \pm 11.51 years). Maximum number of patients fell in the age group of 26 to 35 year (Fig 4). Twelve were males and 10 females (M:F ratio 1.2:1).

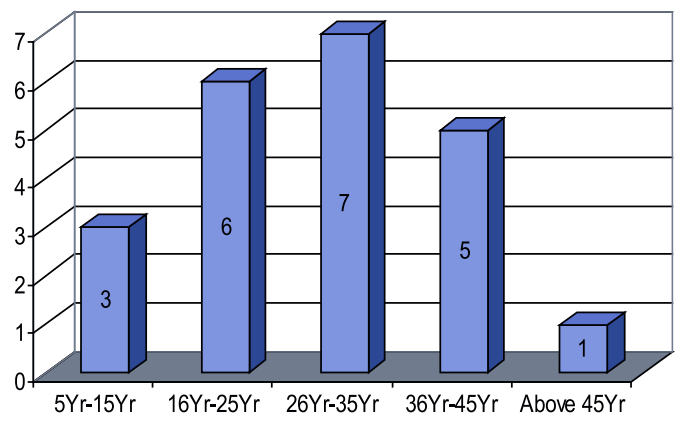

Figure 4. Age wise distribution of $T L(N-22)$ 


\section{Discussion}

T. gondii is a cosmopolitan parasite, ${ }^{8}$ higher prevalence is seen in warm and humid climates. A significant population of these areas harbors low titers of antibody. ${ }^{1}$ The frequency of such infections varies considerably from country to country and within a country. Various Sero-epidemiological studies conducted in Bangladesh indicate the widespread prevalence of parasite in our population. ${ }^{9,10}$

$\mathrm{TL}$ is the most common presentation in acquired toxoplasmosis. ${ }^{11}$ Manifestations are protean, some are asymptomatic, some may present with adenopathy involving multiple sites and symptoms and signs closely mimicking infectious mononucleosis, sometimes lymphoma may also come to differential diagnosis. ${ }^{1,11}$ FNAC has become an integral part of the initial diagnosis and management of patients with lymphadenopathy. ${ }^{12}$ It is important to diagnose the disease or provide clue to diagnosis in FNAC because it can avoid unnecessary surgery ${ }^{11}$ and disease can be totally cured by medical management.

Diagnosis of toxoplasmosis is based on combination of FNAC or tissue biopsy and serological detection of antibody against Toxoplasma. Argyl et al. concluded that identification of tissue cyst is very rare in smears. ${ }^{7}$ In our study one patient had bradyzoites in FNAC smears. The other FNAC findings were presence of tiny collections of epithelioid cells coupled with abundance of TBMs and FCCs in a reactive background and absence of necrosis. These cytological findings in our study were appreciated by the cytopathologists and for confirmation ELISA was done. Diagnosis of TL was initiated after positive serological finding of IgM of Toxoplasma which was found in 22/32 patients. Bilala et al. showed in their study that about $36.7 \%$ of lymphadenopathy patient were having high IgM titer of toxoplasma antibody signifying acute toxoplasmosis. ${ }^{13}$

Toxoplasmosis is not an uncommon cause of lymphadenopathies; in young adults $5-15 \%$ of reactive lymphadenitis may be due to toxoplasmosis. ${ }^{14,15}$ It must be considered in the differential diagnosis of lymphadenopathy. Careful attention to evaluate the indicative cytological features in FNAC smears of affected lymph node can raise the suspicion. The cytological finding, however, must be correlated with positive serological titer, in order to make a definitive diagnosis. In current study $68.75 \%(22 / 32)$ of the suspected cases proved to be TL as confirmed through ELISA.

\section{Conclusion}

TL is more a reality than it is thought of by clinicians or cytopathologists. FNAC smears of lymph node may have adequate clue to its presence which may go unnoticed to an unwary cytopathologist. FNAC smears of lymph nodes should be carefully examined to detect the features of toxoplasmosis. If findings suggest possibility of TL serology should be done to confirm the diagnosis.

Conflict of interest: Nothing to declare.

\section{References}

1. Pathan SK, Francis IM, Das DK, Mallik MK, Sheikh ZA, Hira PR. Fine needle aspiration cytologic diagnosis of TL. A case report with detection of a Toxoplasma bradycyst in a Papanicolaou-stained smear. Acta Cytol. 2003;47:299-303.

2. Bhalekar S, Sirmukaddam S, Bhalekar H, Kundu S. Toxoplasmosis Diagnosed on Fine Needle Aspiration Cytology: A Rare Case Report. BAOJ Pathol 2017;1: 001.

3. Hosokawa S, Kusama Y, Ono T, Mineta H. TL diagnosed by fine-needle aspiration cytology: a rare finding. J Laryngol Otol. 2014;128: 561-64.

4. Jayaram N, Ramaprasad AV, Chethan M, Sujay AR: TL: Analysis of cytologic and histopathologic criteria and correlation with serologic tests. Acta Cytol 1997;41:653-658.

5. Liu Q, Wang Z-D, Huang S-Y, Zhu X-Q. Diagnosis of toxoplasmosis and typing of Toxoplasma gondii. Parasites \& Vectors 2015;8:292.

6. Zaharopoulos P: Demonstration of parasites in TL by fine needle aspiration cytology: Report of two cases. Diagn Cytopathol 2000;22:11-15.

7. Argyle JC, Schumann GB, Kjeldsberg CR, Athens JW: Identification of a toxoplasma cyst by fine-needle aspiration. Am J Clin Pathol 1983;80:256-58.

8. Markell EK, John DT, Krotoski WA (editors): Markell and Voges Medical Parasitology. Eighth edition. Philadelphia, WB Saunders, 1999; pp 161-71.

9. Margia UH, Begum N, Hossain MS, Dey AR, Alam MZ. Seroprevalence of Toxoplasmosis in Women in Mymensingh and Rangpur in Bangladesh: A Hospital Survery: Bangl. J. Vet. Med. 2017; 15 (1): 81-85.

10. Samad MA, Dey BC, Chowdhury NS, Akhtar S, Khan MR. Sero-epidemiological studies on Toxoplasma gondii infection 
in man and animals in Bangladesh. Southeast Asian J Trop Med Public Health1997; June; 28(2): 339-43.

11. Remington J S. Toxoplasmosis in the adult. Bull N Y Acad Med. 1974 Feb; 50: 211-227.

12. Hafez NH, Tahoun NS. Reliability of fine needle aspiration cytology (FNAC) as a diagnostic tool in cases of cervical lymphadenopathy. Journal of the Egyptian National Cancer Institute (2011); 23: 105-114.
13. Bilal JA, Alsammani MA, Ahmed MI. Acute Toxoplasma gondii infection in children with reactive hyperplasia of the cervical lymph nodes. Saudi Med J 2014; 35: 699-703.

14. Krick JA, Remington JS: Current concepts in parasitology: Toxoplasmosis in the adult: An overview. N Engl J Med 1978; 298:550-53

15. Siim JC (ed): Clinical and diagnostic aspects of human acquired toxoplasmosis, Human toxoplasmosis. Copenhagen, Ejna Munksgaard Forlag, 1960, pp 53-79. 